\title{
Summary.
}

The author's method for the separation of lithium from the other alkali metals has been studied with the view to its adaptability to the separation of magnesium from these metals. With some modifications, the procedure has been found to be well adapted to magnesium. The method depends on the progressive precipitation of the sodium and potassium chlorides from a concentrated aqueous solution by the use of alcohol and ether and is divided into 2 stages, ( $\mathrm{r}$ ) in which all but a few $\mathrm{mg}$. is precipitated, and (2) in which the last few mg. is removed from solution.

The method has several advantages, viz., (I) it affords a direct determination of the sodium and potassium chlorides in that they are precipitated firsi (rather than after magnesium as in other methods), (2) the reagents used are readily volatile organic solvents, and (3) no foreign base or salts is introduced as a precipitating agent.

WASTINGTON, D. C.

[CONTRIBdTion From the WOLCOTT GibBs Memorial IAaboRatory, Harvard UNIVERSITY.]

\section{AN INDIRECT METHOD OF DETERMINING THE SPECIFIC HEAT OF DILUTE SOLUTIONS, WITH PRELIMINARY DATA CONCERNING HYDROCHLORIC ACID.}

By Thedore W. Richards and Alian W. Rowh.

Received June 16, 1920.

\section{Method and Apparatus.}

The specific heat of a dilute solution can be determined indirectly from the difference in the heat evolved on diluting a known concentrated solution to a solution of the desired strength at 2 different temperature. ${ }^{1}$ This method rests upon the familiar consequence of the first law of thermodynamics known as Kirchhof's Law, viz.,

$$
K_{M}-K_{M}^{\prime}=\left(U^{\prime}-U\right) / \Delta \theta
$$

In this equation $K_{M}$ and $K^{\prime}{ }_{M}$ represent, respective, the molal heat capacities of the reacting stubstances and of the products, and $U$ and $U^{\prime}$ the re-

${ }^{1}$ Berthelot pointed this out long ago, but did not test it experimentally (Mecanigue chimique, $x, 278$ (1879)). Perhaps the first experimental application of the principle has been made by one of us and A, B. Lamb, Proc. Am. Acad. 40.675 (rgos). As these authors pointed out, the process is a very accurate one, the errors being divided instead of multiplled by it. Tucker's interesting work deals primarily with corn. centrated solutions (Phil. Trans. [A] 215, 319 (I915)). This was published some time after the present work (the publication of which was much delayed by the war) was completed. The "continuous flow" method used for heats, of neutralization by J. B. Dickson at the suggestion of A. A. Noyes and under the direction of F. G. Keyes might be used for work of this kind, but has not yet been so employed (Thesis submitted to Faculty of Mass. Inst. Tech., rgr 7 ). 
spective total energy changes-in the case in hand, the heats of dilutionat the temperatures $\theta$ and $(\theta+\Delta \theta)$.

According to this principle, when once the heat capacity of a concentrated solution has been determined, that of any less concentrated solution can be obtained merely by the measurement of 2 heats of dilution. Hence the method is highly convenient, because heats of dilution are easier to determine than specific heats. The present paper exemplifies the experimental use of the method, and confirms the specific heats of a number of solutions needed in other work.

The appparatus was planned in such a way that the 2 liquids to be mixed should be at precisely the same temperature before mixing. In principle similar to those employed in 1905 by one of us, first with the help of A. B. Lamb ${ }^{1}$ and later in improved fortn with the help of I. J. Henderson, ${ }^{2}$ it embodied the further improvements which we have already described and pictured. ${ }^{3}$ In this apparatus the concentrated solution was enclosed in an inner platinum receptacle partly immersed beneath the water in the calorimeter; when both liquids had attained exactly the same temperature, the inner receptacle was put into communication with the outer, and by suitable stirring the fluids were mixed. The thermochemical measurement was accomplished adiabatically.

Several combinations of calorimeter apparatus were necessary in order to accommodate the varying proportions of liquids. For the main receptacle, either one of two cylindrical platinim cans was used; the first, $A$, having a capacity of 1.4 liters and the second, $B$, having a capacity about half of this amount. These cans contained in each case the water to serve as diluent.

According to the amount of concentrated solution to be diluted, one of 4 inner receptacles was employed. Each of these inner receptacles answered in general to the description already given, but they varied in volume from 0.7 liter to 0.025 liter. A detailed description of each follows.

a. This inner receptacle (used only with Can $A$ ) had a capacity of about 0.7 liter, making it possible to mix equal volumes. The great diffculty in this case is to conduct the mixing in such a way as to cause the temaperature to rise regularly in all parts of the calorimeter. If this is not accomplished, irregular losses of heat are bound to occur, no matter what calorimetric method is used. Since the combination $A$ a was used not ouly in this work, but also in many determinations of the heat of neutral-

Loc. cii.

T. W. Richards and I. J. Henderson, Proc. Am. Acad., 4I, I (rgos); Z. physik. Chems, 52,560 (1905).

\& T. W. Richards, A. W. Rowe and L. I. Burgess, THis JourNal, 32, x I80 (1910). Tucker's apparatus (lot. cit.) was a modified form of this arrangement, embodying the same idea. 
ization, its manner of use may be described in full. It is indicated in the sectional diagram, Fig. I. The large platinum calorimeter can, $A$, was placed within a "stxbmarine" jacketing vessel $(S)$ protected by an anmular air space which was maintained by the use of thin cork wedges at the bottom and sides. A 2-stage narrow platinum ring. stirrer, $O$, alternating 45 times per minute, thoroughly agitated the liquid without causing appreciable heating efect. The stirrer was suspended upon hard rubber rods of the smallest possible diameter in order to minimize the pumping of air through the copper tubes and consequent extraneous heat changes. Circulation of air through the tube was prevented by loose plizgs of cotton wool (not shown in the diagram). The inner edges of the stirrer carried several fine platinum wires $(f)$ which effectually prevented its catching on the edge of the inside receptacle.

This vessel, which contained the solution to be diluted, was mounted upon stout

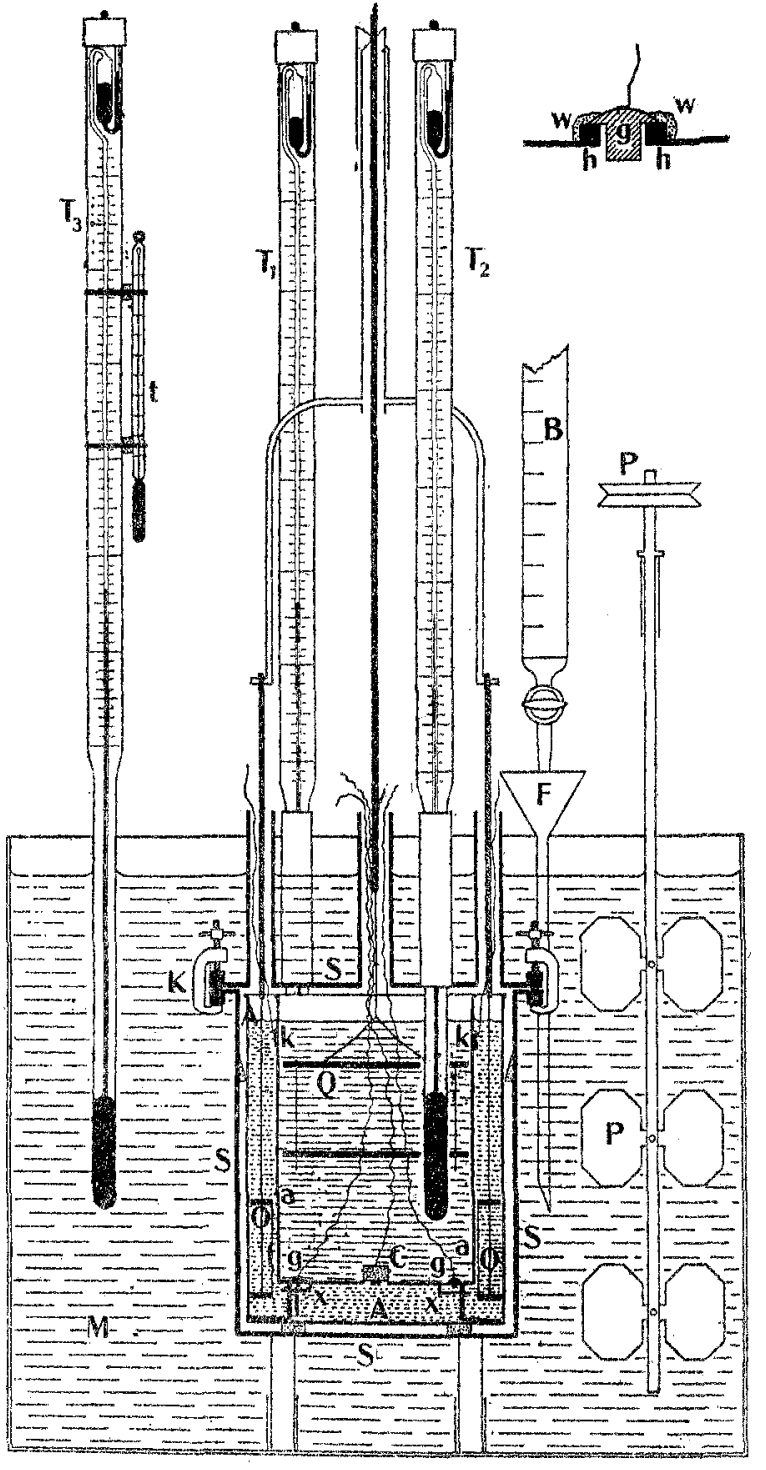

Fig. I. - Adiabatic thermochemical apparatus for mixing equal volumes of liquids. It consists of a calorimeter $A$ to contain one of the liquids and an inner vessel $a$ to contain the other, with valves $C, g, g, k, k$ for communication. Its working is fully explained in the letter press. The small valves $g, g$, are show: in the greatly enlarged detail in the upper right-hand corret. 
platinum legs of $\mathrm{L}$ shape, the outer circumference of which was that of the inner circumference of the calorimeter. As is evident from the figure, the amount of lateral clearance of the calorimeter stirrer was very slight, and this centering device was necessary to avoid cramping when in action. Three lugs at the upper edge of the inner can (not shown in the diagram) were found to be of assistance in preventing any tilting of the inner receptacle $(a)$. The floor of this latter was perforated with 3 short tubes, one $(C)$ of large diameter- $.5 \mathrm{~cm}$.-closed by the small rubber stopper; and two of small bore- $0.15 \mathrm{~cm}$.-closed by small platinum valves $(g)$, all made fast with beeswax. The detail of the smaller valves can be seen to better advantage in the greatly enlarged detailed drawing in the upper right-hand corner. The platinum plug $g$ rested in the opening $h h$. Beeswax (wrw), easily melted into place with a hot glass rod, cemented them together, making a tight joint impervious to water. All the valves were manipulated by means of attached platinum wires. The small platinum baffles $(x, x)$ served to deflect the outflowing liquid from the bottom of the calorimeter. In addition to the valves already described, 2 more $(k k)$ were placed in the upper part of the inner container and were of the same size and general description as the large valve in the container floor. A 2-stage platinum stirrer $Q$, alternating 45 times per minute, agitated the contents of the inner can, working in opposition to that in the outer vessel and producing a pumping effect in the liquid when the valves were open. The suspension was through a rod of hard rubber of minimum diameter. Two carefully calibrated thermometers $\left(T_{1} T_{2}\right)$ were at first used, one in the water in the annular space between the two cans, and one in the solution in the inner receptacle.

The external bath was brought to within $0 . \mathrm{I}^{\circ}$ of the proposed initial temperature, the valves of the inner container were then made fast, the appropriate amount of water (about 0.55 liter) was placed in the outer vessel, and the solution to be diluted was placed in the closed inner vessel after making sure that the valves were all tight. The liquids in both the inner vessel and the outer vessel were weighed and the apparatus containing the liquids assembled. The stirrers were put in place, the lugs arranged, the gasket added, the case cover put on, the set screws (K) tightened and the level of the outer bath restored to the position shown in the drawing. The rest of the apparatus was then rapidly assembled. The alternating stirrers were actuated by metal rods working in guides which insured that uniformity of position of the moving parts, essential to their perfect functioning.

In a few minutes after the stirrers were set in motion, the calorimetric system was thermally homogeneous- the temperature of the outside bath being carefully regulated to accord with that of the calorimeter. Under 
these conditions the calorimetric temperature would remain constant for an indefinite period. After a 10- to 15 -minute interval of constant readings, the inner thermometer, $T_{2}$, was carefully read. On an upstroke of the inner stirrer, the small platinum valves were withdrawn and a portion of the acid was automatically sucked up into the inner chamber. ${ }^{1}$ The pumping effect of the 2 stirrers now effected a gradual mixing of the 2 solutions, which caused a steady rise of temperature in both the inner and outer chambers. So perfect was the interchange and so efficient the mixing that at no time during an experiment was there an important difference in temperature $\left(0.020-0.030^{\circ}\right)$ between the inner and outer liquids, ${ }^{2}$ even when a reaction involving a $4^{\circ}$ total rise was concerned. This observation was further confirmed by raising and lowering the thermometers, these differences producing no essential change in their readings. ${ }^{3}$ When the mixing had approached completion and the speed of change had greatly diminished, the large rubber valve in the floor and, one minute later, those in the walls were opened. Complete equalization was speedily realized, as was indicated by constant readings of the thermometers. During the change of temperature in the calorimeter, the temperature of the jacket was correspondingly altered, the difference between the two at no time exceeding a few hundredths of a degree. After a Io- or I5-minute interval of constant readings, the inner thermometer was again carefully read, the rise from the initial constant point constituting the value $\Delta t_{1}$ or $\Delta t_{2}$ of the subsequent computations. It remained only to break down, wash, dry and reassemble the apparatus for a new experiment.

$b$. The second dilution receptacle has been already described and pictured in a previous article. ${ }^{4}$ This contained about 0.25 liter, was wide open at the top, and had a single small opening in the bottom. It was suspended on 3 stout, platinum wires, connected with thin hard-rubber tubes and rods above. The single lower small opening was stopped by means of a small rubber stopper; from which a wire for withdrawal projected through the cover of the calorimeter, just as with the central orifice in receptacle $a$. The weighed quantity of concentrated liquid in the inner receptacle was stirred by a 2 -stage platinum reciprocating stirrer, which moved always in the direction opposite to that of the annular reciprocating stirret in the outer concentric vessel. The calculated amount of water was placed in the platinum calorimeter, that of the solution in the

1 The apparatus was so designed that with the originally computed amounts of liquid, the outer level was slightly the higher.

2When this fact had been thoroughly established by experiment, the use of the second (outer) thermometer $\left(T_{1}\right)$ was discontinued.

3 The difference in hydrostatic pressure thus produced were not enongh to effect the thermometer readings by $0.00 \mathrm{r}^{\circ}$.

4 Richards, Rowe and Burgess, loc. cit., p. I 79. 
receptacle $b$, and the apparatus was assembled in the "submarine" ves" sel exactly as in the case of $a$. The conduct of the determination did not: differ essentially from that described under the preceding head, except that, before the conclusion, the top of the receptacle $b$ was lowered beneath the liquid level to insure complete mixing.

c. The third receptacle, $c$, was a gold vessel similar in all details except size and material to the preceding, and contained about roo $\mathrm{cc}$.

$d$. The fourth receptacle, $d$, was a small platinum container holding about $25 \mathrm{cc}$, similar to $b$ and $c$.

The heat capacities of these several outfits, with the appropriate stirrers, thermometers, etc., in the combinations employed, were as follows.

$$
\begin{aligned}
& A a, 19.0 ; A b, \text { I5.4; } A c, 16.1 ; A d, 12.4 . \\
& B b, \text { Ix.0; } B C, 1 \times .7 ; B d, 7.9 . \quad \text { (cal. } /{ }^{\circ} \mathrm{C} \text { ). }
\end{aligned}
$$

When the large calorimeter, $A$, was used, either with $a, b$, or $c$ as accessory, the amounts of solution and water taken were such that the total heat capacity was usually in the neighborhood of rroo cal. $/{ }^{\circ} \mathrm{C}$; whenever the small calorimeter, $B$, was used, the corresponding figure was about $550 \mathrm{cal} . /{ }^{\circ} \mathrm{C}$. With the former outfit, the solid parts of the calorimeter averaged about $\times .5 \%$ of the total heat capacity; with the latter outfit, about $2.0 \%$. That is to say, the factor $f$ (referred to later) is $x .0 r 5$ in one case and $\mathrm{x} .02$ in the other. These approximate values are usually exact enough to correct the actual values of $\left(\Delta t_{2}-\Delta t_{1}\right)$ to the ideal values which would have been observed if the calorimeter had possessed zero heat capacity, as will be seen more clearly soon.

The mercury-in-glass thermometer used for measuring the temperature changes had been especially constructed for the purpose by an expert. The bulb had a capacity of nearly 4 milliliters, and the scale (which showed a range of temperature from $15.5^{\circ}$ to $20.8^{\circ}$ ) was $40 \mathrm{~cm}$. in length. Each degree was divided into hundredths by fine, clear lines: making the reading of $0.0005^{\circ}$ a matter of ease and certainty. The thermometer was originally filled under an atmosphere of hydrogen to obviate the possi. ble formation of a film of oxide. This precaution instred a freely moving thread, which was gently tapped before a reading. The scale was carefully calibrated in the usual manner by comparison with 2 normal thermometers (Baudin, Nos. I5200 and 15276). For work of this nature, where small temperature intervals are to be measured at different parts of the scale, it is evident that a large number of adjacent points must be determined if reasonable accuracy is to be secured, especially in those parts of the column which show irregularity. Clearly the usual method of calibrating thermometers by comparison with a standard at a few points only in the scale may tend to give misleading data for some of the intervening points. Of course, when (as in this case) the temperature 
intervals are small, a small error in reading is a large per cent. of the whole. Although we did our best with the means at our disposal to effect an adequate standardization at frequent intervals over the whole scale, we believe this to have been the least satisfactory part of the work. The electrical methods, when properly outfitted and handled with elaborate precaution, are better in such cases; but at the date of making these determinations (1912) we had no electrical apparatus which would yield a degree of precision equal to that of the mercury-in-glass instrument. The description of the general method will, however, serve our main purpose, even if the final figures may ultimately need slight revision.

\section{The Data of a Typical Determination in Full.}

A specimen series of experiments may be given together with the calculations in order to show the magnitude of the quantities concerned, the method of experiment, and the details of the calculation. The case of hydrochloric acid is chosen. The original solution contained $9.174 \%$ of pure hydrogen chloride (the mean of 2 gravimetric analyses giving 9.173 and 9.175 , respectively) and, therefore, has the concentration $\mathrm{HCl}$, $20.03 \mathrm{H}_{2} \mathrm{O}$. This was diluted in 2 series (of 3 experiments each) to the concentration $\mathrm{HCl} \cdot 100 \mathrm{H}_{2} \mathrm{O}$, at 2 different temperatures.

TABLE I.

Heat of Dilution of $\mathrm{HCl} .2 \mathrm{OH}_{2} \mathrm{O}$ to $\mathrm{HCl} .100 \mathrm{H}_{2} \mathrm{O}$.

(Heat Capacity of Solid Parts of Calorimeter $=15.4 \mathrm{Cal} . / \mathrm{t}$.)

\begin{tabular}{|c|c|c|c|c|c|c|}
\hline \multirow{2}{*}{ Expt. } & \multirow{2}{*}{$\underset{\mathrm{G}}{\mathrm{HCl}}$ sol. } & \multirow{2}{*}{$\begin{array}{l}\mathrm{H}_{2} \mathrm{O} . \\
\mathrm{G} .\end{array}$} & \multicolumn{2}{|c|}{$\begin{array}{l}\text { At the lower } \\
\text { temperature. }\end{array}$} & \multicolumn{2}{|c|}{$\begin{array}{l}\text { At the higher } \\
\text { temperature. }\end{array}$} \\
\hline & & & $i$ & $\overline{\Delta t_{1} .}$ & ta. & $\overline{\Delta t_{2}}$ \\
\hline R... & 225.0 & $8 \pi 7 \cdot 3$ & $15.80^{\circ}$ & $+0.249^{\circ}$ & $20.4 I$ & $+0.266^{\circ}$ \\
\hline $2 \ldots \ldots \ldots \ldots \ldots \ldots \ldots$ & 225.0 & $8 \times 7 \cdot 3$ & $15.84^{\circ}$ & $0.249^{\circ}$ & 20.49 & $0.267^{\circ}$ \\
\hline $3 \ldots \ldots \ldots \ldots \ldots \ldots$ & 225.0 & $817 \cdot 3$ & $15.86^{\circ}$ & $0.249^{\circ}$ & 20.47 & $0.267^{\circ}$ \\
\hline & & erage & $15.83^{\circ}$ & $0.2490^{\circ}$ & 20.46 & 0.2667 \\
\hline
\end{tabular}

In order to calculate from these figures the specific heat of the dilute solution, that of the original more concentrated acid $\mathrm{HCl}_{2} 2 \mathrm{OH}_{2} \mathrm{O}$ must be known. This was found by the method described in a preceding paper $^{\text {i }}-a$ definite weight of the acid being raised in temperature by the heat given out by neutralization of a known weight of pure dil. sulfuric acid in an enclosed, sunken receptacle, and the result being compared with a similar procedure with a definite weight of pure water calculated to the same temperature. The calorimetric outfit had a total heat capacity of $139.09 \mathrm{cal} . /{ }^{\circ} \mathrm{C}$. in addition to that of the liquid to be determined.

1 T. W. Richards andA. W. Rowe, Proc. Am. Acad., 49, 773 (x9r3); Z. physik. Chetr. $84,585(1913)$. See especially pp. 190 and 60 r respectively. 
TABLE II.

Specific Heat of $\mathrm{HCl} .2 \mathrm{OH}_{2} \mathrm{O}$.

(a) Averages of Experiments with Pure Water."

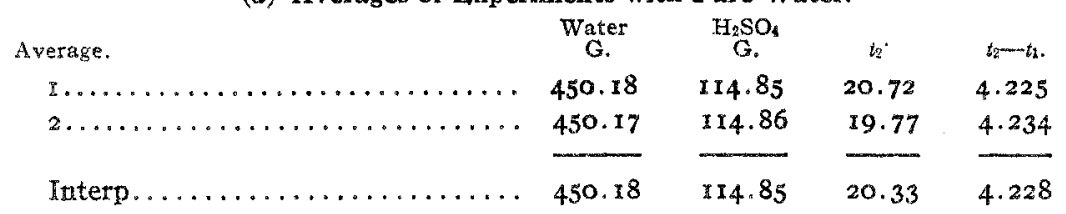

(b) Individual Experiments with the Acid Solution.

\begin{tabular}{|c|c|c|c|c|c|}
\hline Expt. & $\mathrm{HCl} .20 \mathrm{H}_{2} \mathrm{O}$. & $\underset{\mathrm{G}}{\mathrm{H}_{2} \mathrm{SO}_{4}}$ & $t_{2}$ & $t_{2}-i_{1}$ & $\begin{array}{c}\mathrm{Sp} . \mathrm{Ht}_{\mathrm{t}} \\
\mathrm{HC} .20 .03 \mathrm{H}_{2} \mathrm{O}\end{array}$ \\
\hline$r \ldots \ldots \ldots \ldots \ldots$ & 503.24 & 114.86 & $20.36^{\circ}$ & $4.400^{\circ}$ & 0.8489 \\
\hline $2 \ldots \ldots \ldots \ldots \ldots \ldots$ & 503.26 & 114.87 & $20.13^{\circ}$ & $4.402^{\circ}$ & $0.849 \mathrm{I}$ \\
\hline $3 \ldots \ldots \ldots \ldots \ldots \ldots$ & 503.25 & II 4.85 & $20.05^{\circ}$ & $4.402^{\circ}$ & 0.8492 \\
\hline $4 \ldots \ldots \ldots \ldots, \ldots$, & 503.24 & $x 14.86$ & $20.62^{\circ}$ & $4.398^{\circ}$ & 0.8485 \\
\hline $5 \ldots \ldots \ldots \ldots \ldots$ & 503.26 & 114.86 & $20.27^{\circ}$ & $4.401^{\circ}$ & 0.8488 \\
\hline $6 \ldots \ldots \ldots \ldots \ldots$ & 503.25 & 114.87 & $20.54^{\circ}$ & $4.397^{\circ}$ & 0.8490 \\
\hline Avera & 503.25 & $\mathrm{rr}_{4} .86$ & 20.33 & 4.400 & $0.8489^{\circ}$ \\
\hline
\end{tabular}

"T. W. Richards and A. W. Rowe, Proc. Am. Acad., 49, 191 (1913).

${ }^{5}$ An earlier determination of this quantity by a somewhat less satisfactory method (ibid, 43,475 (1908)), gave the nearly identical value, 0.8488 .

These 6 individual experiments evidently agree closely. The method of calculating the values given in the last column is exemplified as follows. From the interpolated value for water at $t_{2}=20.33^{\circ}$ and the average data of Series $(b)$, the following equation gives the specific heat $x$ of the more concentrated solution:

$(503.25 x+139.09) 4.400=(450.18+139.09) 4.228 \times 1.0001$ in which the last factor takes account of the fact that slightly less sulfuric acid was neutralized in Series $(a)$ than in Series $(b)$. Hence, $x=0.8489$, the specific heat of $\mathrm{HCl} .20 .03 \mathrm{H}_{2} \mathrm{O}$. Corrected to exactly $\mathrm{HCl} .20$. $00 \mathrm{H}_{2} \mathrm{O}$ this value becomes 0.8487 .

\section{The Calculation of the Result for the Dilute Solution.}

The data are now all at hand for the calculation of the specific heat of the more dilute acid, and we may turn again to the data of Table I. To assist in the correct substitution of the several quantities in the Kirchhoff equation, it is well to define each quantity and use a definite notation throughout, as follows.

$U$ and $U^{\prime}=$ heats of dilution of amounts employed, at lower and higher temperatures, respectively.

$U_{M}$ and $U^{\prime}{ }_{M}=$ heats of dilution with molal amounts, at lower and higher temperatures, respectively.

$=$ molal weight of total solution (e. g., $\mathrm{HCl} .100 \mathrm{H}_{2} \mathrm{O}=$ 1838.07). 
$=\theta-273 . I=$ centigrade temperature after difution at lower temperature.

$=\theta+\Delta \theta-273.1=$ centrigrade temperature after dilution at higher temperature. ${ }^{1}$

$=t_{2}-t_{1}=$ range of temperature covered by Kirchhoff equation.

$\Delta t_{1} \quad=$ rise of temperature on dilution at lower temperature.

$\Delta t_{2} \quad=$ rise of temperature on dilution at upper temperature.

$f \quad=$ factor necessary to correct $K_{1}$ and $K_{2}$ for heat capacity of calorimeter vessels.

$f^{\prime}=\mathrm{r} .0005-0.00025(i-\mathrm{I} 6)=$ another factor taking account of changing specific heat of water.

$n \quad=$ number of mols of reacting substance in experiment.

$K_{1}$ and $K_{2} \quad=$ initial capacities of whole system over the ranges $\Delta i^{\circ}{ }_{1}$ and $\Delta t_{2}^{\circ}$, respectively.

$K=$ average initial heat capacity of reacting material (excluding calorimeter) between $t_{1}^{\circ}$ and $t_{2}^{\circ}$.

$K^{\prime} \quad=$ average final heat capacity of reacted material (excluding calorimeter) between $t_{1}^{\circ}$ and $t_{2}^{\circ}$.

$K_{\mathrm{M}}$ and $K_{\mathrm{M}}^{\prime}=K / n$ and $K^{\prime} / n=$ corresponding heat capacities of molal quantities.

$S_{c} \quad=$ specific heat of initial concentrated solution.

$S_{d} \quad=$ specific heat of final dilute solution.

(Both referred to water as unity over the same range of temperature.) (The atomic weights are those of the current International Table. $\mathrm{H}_{2} \mathrm{O}=18.016 ; \mathrm{HCl}=36.47$. .

The quantity of heat $(U)$ actually evolved in the calorimeter on dilution at $t_{1}$ is $K_{1} \Delta t_{1}$, and that ( $\left.U^{\prime}\right)$ at $t_{2}$ is $K_{2} \Delta t_{2}$. Hence the Kirchhoff calculation takes the following exact form:

$$
K-K^{\prime}=\frac{K_{2} \Delta t_{2}-K_{1} \Delta t_{1}}{\Delta \theta}
$$

now

$$
S_{d}=\frac{K^{\prime}}{M n}=\frac{K-\left(K_{2} \Delta t_{2}-K_{1} \Delta t_{1}\right) / \Delta \theta}{M n}
$$

or

$$
S_{\dot{\alpha}}=\frac{K}{M n}-\frac{K_{2} \Delta t_{2}-K_{1} \Delta t_{1}}{M n \Delta \theta}
$$

Another less exact but often adequate and more convenient mode of computing the results may also be given. As an approximation, Equation 2 may be simplified by taking account of the fact that $K_{1}$ and $K_{2}$ differ

${ }^{1}$ Since the heat capacities of the factors of the reaction were used in making the calculation, the final temperature of each dilution is that which must be called the temperature of the experiment (Richards, Tris Jouknal, 25, 209 (1903)). 
(when $\Delta \theta=4^{\circ}$ ) by only about $0.1 \%$ and that each is essentially equal to $K f$. When the deviation of $0 . r \%$ is too small to be of any account, the Kirchhoff Equation (2) may be taken as

$$
K-K^{\prime}=\frac{K f\left(\Delta t_{2}-\Delta t_{1}\right)}{\Delta \theta}
$$

which affords the most convenient means of calculating the heat capacity change from the small rises of temperature observed on dilution at 2 temperatures. The equation is not sufficiently accurate in this form if $\Delta t_{1}, \Delta t_{2}$ or $\Delta \theta$ are large.

The factor $f$ was computed by comparison of heat capacities, but it may be just as well considered in relation to the temperature changes. Evidently, by multiplying the two $\Delta t$ values by this factor we shall obtain the amounts which the temperature would have risen if the calorimeter had been an ideal one, without heat capacity. The result $(f \Delta t)$ will be entirely independent of the size or nature of the apparatus, and will hold for any amounts of the two liquids, provided only that they are in the definite proportion corresponding to the given degree of dilution.

Hence the approximate calculation with Equation 5 may be carried out at once on a gram molecular basis. Substituting the appropriate quantities of the present case in Equation 5, we find

$$
K_{M}-K_{M}^{\prime}=\frac{1778.2 \times 1.015\left(0.2667^{\circ}-0.249^{\circ}\right)}{4.63^{\circ}}=6.9 \mathrm{cal} .{ }^{\circ} \mathrm{C}
$$

The molal heat capacity of $K_{\mathrm{M}}$ of the factors ( $\mathrm{HCl} .2 \mathrm{O} \mathrm{H}_{2} \mathrm{O}+80 \mathrm{H}_{2} \mathrm{O}$ ) was $396.8 \times 0.849+1441.3=1778.2$. Hence that of the product $K_{M}^{\prime}=1778.2-6.9=177 \mathrm{r} . \mathrm{I}$. This number is the molal heat capacity of $\mathrm{HCl}$. $100 \mathrm{H}_{2} \mathrm{O}$. The weight being $1838 . x$, the specific heat of $\mathrm{HCl}, 100 \mathrm{H}_{2} \mathrm{O}$ referred to water over the same range of temperature must be $1771 . x / 1838.1=0.9636=S_{d}$. The error in this result (caused by the fact that the changing specific heat of water is not considered in it), is less than one in the last place of decimals. This error may be corrected by strbtracting from the quantity $K_{\mathrm{M}}-K_{\mathrm{M}}^{\prime}$, a small correction numerically equal to $\mathrm{I} / 4000$ of $K_{\mathrm{M}} \Delta t$, which takes account of the change in the specific heat of water between $t_{1}$ and $t_{2}$.

The result 0.9636 just given agrees well with an earlier direct determination $(0.9634)$ of the specific heat of this solution. The closeness of agreement is indeed partly accidental since the possible experimental error might have led to a somewhat widet divergence.

Similarly, an approximate but usually adequate method may be used for calculating $U_{\mathrm{M}}$ and $U^{\prime}{ }_{\mathrm{M}}$ (which are, respectively, equal to $K_{1} \Delta t_{1} / n$ and $\left.K_{2} \Delta t_{2} / n\right)$. The details of $K_{1}, K_{2}$ and $n$ are bulky, and accordingly in

The heat capacity of water at $16^{\circ}$ may be taken as $0.05 \%$ greater and that at $20^{\circ} 250.05^{\circ}$ less, than the average value over the range $16-20^{\circ}$, 
the table for the sake of economizing space $K_{M}$ alone is recorded. The quantity $K_{\mathrm{M}}$ may be reduced to its value at any temperature $(t)$ between $16^{\circ}$ and $20^{\circ}$ through multiplication by a factor (almost unity) $f^{\prime}=1.0005-0.00025(t-16) .^{1}$ This factor in most cases produces so little effect that it is applied below only for the sake of completeness.

\section{Data for Various Dilutions of Hydrochloric Acid.}

The details concerning the manipulation and essential data of a single case having been given, the outcome of a number of experiments involving the dilution of hydrochloric acid may be very briefly detailed.

Two fairly concentrated solutions were used in the dilution experiment with hydrochloric acid. ${ }^{2}$ The first $\left(\mathrm{HCl} .10 \mathrm{H}_{2} \mathrm{O}\right)$ was taken as $0.75^{2}$, a result which depends chiefly upon Thomsen's observed value 0.749 and Marignac's $0.760^{4}$ giving the former about twice the weight of the latter. Sundry theoretical considerations which need not be detailed here support this value. The second hydrochloric acid solution ( $\mathrm{HCl}$.20$\mathrm{H}_{2} \mathrm{O}$ ) was found to have a specific heat 0.849 in the experiments detailed in Table II. These values for the specific heats were used in calculating the heat capacities of the factors in the reaction; they need not be known very accurately, since the concentrated solutions, as a rule, formed but a small part of the total heat capacity.

The values $\Delta t_{1}$ and $\Delta t_{2}$ (the actual observed rises of temperature of the calorimeter) were each the result of an average of at least 2 determina tions, and sometimes of 3 or 4 , when there seemed to be any doubt about the value. The experiments already given are typical. Apart from the possible errors in the standardization of the thermometer, these figures can hardly be in error more than $0.0005^{\circ}$.

TABLE III.

Observations Giving Rise of Temperature on Dilution at Two Different Temperatures.

\begin{tabular}{|c|c|c|c|c|c|c|}
\hline $\begin{array}{l}\text { Thactors in Reaction. } \\
\mathrm{HCl} . \mathrm{IOH}_{2} \mathrm{O}+{ }_{15} \mathrm{H}_{2} \mathrm{O} \ldots \ldots \ldots\end{array}$ & $\begin{array}{c}\text { Calo. } \\
\text { rimeter. } \\
\text { B b }\end{array}$ & $\begin{array}{c}0_{2}^{t_{2}} . \\
19.65\end{array}$ & 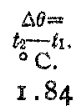 & $\begin{array}{l}\stackrel{\Delta t_{1} .}{C} . \\
\text { I. } 5835\end{array}$ & $\begin{array}{c}\Delta u_{0} \\
\text { I. } 6075\end{array}$ & $\begin{array}{l}\Delta t_{{ }_{0}}-\Delta t_{1} . \\
0.0240\end{array}$ \\
\hline $\mathrm{HCl} \mathrm{IOH}_{2} \mathrm{O}+4 \mathrm{OH}_{2} \mathrm{O}$. & $A b$ & 19.75 & 2.75 & 1.0245 & $x .0550$ & 0.0305 \\
\hline $\mathrm{HCl} 1 \mathrm{OH}_{2} \mathrm{O}+9 \mathrm{OH}_{2} \mathrm{O}$. & A $c$ & 19.85 & $3 \cdot 36$ & 0.5720 & 0.5975 & 0.0255 \\
\hline $\mathrm{HCl}_{2} 2 \mathrm{OH}_{2} \mathrm{O}+8 \mathrm{oH}_{2} \mathrm{O}$. & A. $b$ & 19.92 & $4 \cdot 1 x$ & 0.2490 & 0.2655 & $0.0 \pm 65$ \\
\hline $\mathrm{HCl} .2 \mathrm{OH}_{2} \mathrm{O}+8 \mathrm{OH}_{2} \mathrm{O}$. & $A b$ & 20.69 & 4.63 & 0.2490 & 0.2667 & 0.0177 \\
\hline $\mathrm{HCl} \cdot \mathrm{OOH}_{2} \mathrm{O}+\mathrm{IgOH}_{2} \mathrm{O}$. & Ac & 19.83 & 3.74 & 0.3053 & 0.3190 & $0.0 \times 37$ \\
\hline $\mathrm{HCl} 20 \mathrm{H}_{2} \mathrm{O}+18 \mathrm{OH}_{2} \mathrm{O}$. & $A b$ & 20.31 & 4.51 & $0.14 \times 7$ & 0.1520 & 0.0103 \\
\hline $\mathrm{HCl}$. & A $c$ & 19.88 & $3 \cdot 58$ & 0.1595 & 0.1670 & 0.0075 \\
\hline $\mathrm{HCl} . \mathrm{IOH}_{2} \mathrm{O}+790 \mathrm{H}_{2} \mathrm{O}$. & $A d$ & 18.19 & & 0.084 & & \\
\hline
\end{tabular}

The results given in this table may be used for calculating 2 different but allied quantities, namely the heat of dilution on the one hand and the

"Of course this is merely approximate, the true relation being curved, not linear.

Loc. cit., p. 198 .

"J. Thomsen, "Thermochemische Untersuchumgen;" I, p. 38.

- Oeluvres Comp1. 2, 238 . 
specific heat of the dilute solution on the other hand. Considering the exposition already given it will be sufficient to give tables detailing these results without further explanation. Immediately following is the table giving the molal heat of dilution. Attention is called to the fact that the values of $U_{M}$ and $U^{\prime}{ }_{M}$ may be calculated not only from the fashion indicated below, but also from the data given according to the equation $U_{\mathrm{M}}=K_{\mathrm{M}} f^{\prime} \Delta t_{1}$, with the sufficient accuracy for the present purpose. On this account the detailed data for $K_{1}, K_{2}$, and $n$ need not be given herewith, although they were used in the actual calculation of the $U$ values.

TABLE IV.

Molal Heat of Dilution of Hydrochloric Acid.

\begin{tabular}{|c|c|c|c|c|c|c|}
\hline Factors in Reaction. & $\Delta \theta$. & $\begin{array}{c}K_{M_{0}} \\
\text { (at I } 8^{\circ} \text {.) }\end{array}$ & $\underset{\substack{U_{\mathrm{M}}=\\
K_{\mathrm{l}} \Delta h_{\mathrm{L}} / n_{\mathrm{L}}}}{.}$ & $\begin{array}{c}U_{M}= \\
K_{2} \Delta t_{2} / n_{1}\end{array}$ & $\begin{array}{c}\Delta U / \Delta \theta= \\
\left(K_{M^{-}}-K_{M}^{\prime}\right)\end{array}$ & $t_{20}^{\circ}$. \\
\hline $\mathrm{HCl} \cdot 10 \mathrm{H}_{2} \mathrm{O}+\mathrm{I}_{5} \mathrm{H}_{2} \mathrm{O} \ldots$ & I. 84 & 433.1 & $70 \mathrm{r}$ & $7 \times 2$ & $5 \cdot 9$ & 714 \\
\hline $\mathrm{HCl} \cdot 1 \mathrm{OH}_{2} \mathrm{O}+4 \mathrm{OH}_{2} \mathrm{O} \ldots$ & 2.75 & 883.5 & 918.5 & 946 & xo.o & 949 \\
\hline $\mathrm{HCl} \cdot 1 \mathrm{OH}_{2} \mathrm{O}+90 \mathrm{H}_{2} \mathrm{O} \ldots$ & $3 \cdot 36$ & 1784.3 & 1036 & $108 \mathrm{r}$ & 13.3 & 1082 \\
\hline $\mathrm{HCl} 1.2 \mathrm{OH}_{2} \mathrm{O}+8 \mathrm{oH}_{2} \mathrm{O} \ldots$ & $4 \cdot 11$ & 1778.2 & 449.8 & 479.0 & $7 \cdot x$ & 480 \\
\hline $\mathrm{HCl} .2 \mathrm{OH}_{2} \mathrm{O}+8 \mathrm{oH}_{2} \mathrm{O} \ldots$ & 4.63 & $\times 77^{8} .2$ & 449.8 & $481 \cdot 4$ & 6.8 & 477 \\
\hline $\mathrm{HCl} \cdot \mathrm{IOH}_{2} \mathrm{O}+190 \mathrm{H}_{2} \mathrm{O}$. & 3.74 & 3585.9 & IIIO & II59 & $13 \cdot x$ & $116 \mathrm{I}$ \\
\hline $\mathrm{HCl} .2 \mathrm{OH}_{2} \mathrm{O}+\mathrm{r}_{80 \mathrm{OH}_{2}} \mathrm{O}$. & $4 \cdot 5 \pi$ & $3579 \cdot 4$ & 515 & 552 & 8.2 & 549 \\
\hline $\mathrm{HCl} \cdot \mathrm{rOH}_{2} \mathrm{O}+39 \mathrm{OH}_{2} \mathrm{O}$. . & $3 \cdot 5^{8}$ & 7189.1 & $x \times 63$ & $12 \pm 7$ & I $5 . I$ & $12 \times 9$ \\
\hline $\mathrm{HCl} .1 \mathrm{OH}_{2} \mathrm{O}+79 \mathrm{OH}_{2} \mathrm{O}$. & * & * & 1220 & . & I $5 \cdot 3^{4}$ & $1247^{a}$ \\
\hline
\end{tabular}

Yet another table records the steps in the calculation of the specific heat of the dilute solutions as follows.

TABLE V.

Specific Heat of Dilute Hydrochloric Acid of Several Concentrations.

\begin{tabular}{|c|c|c|c|c|c|c|}
\hline Fact & $\begin{array}{c}K_{\mathrm{M}=\text { Heat }} \\
\text { Cap. of } \\
\text { Factors. }\end{array}$ & $K_{\mathrm{M}}$ & $\begin{array}{c}K^{\prime} M= \\
\text { Heat } \\
\text { Cap. of } \\
\text { Product. }\end{array}$ & $\begin{array}{c}\text { Molal } \\
\text { Wt. } \\
\text { Product. } \\
\text { M. }\end{array}$ & & $\begin{array}{c}\text { Sp. Keat } \\
\text { Product. } \\
S_{d=} \\
K_{M}^{\prime} / M .\end{array}$ \\
\hline & & & $427 \cdot 3$ & 4.86 & & \\
\hline $\mathrm{Cl}$ & & IO. 0 & 873 & & & \\
\hline $\mathrm{iCl}$ & 1784.3 & $13 \cdot 3$ & 9 & & & \\
\hline $\mathrm{C}$ & 177 & & 6 & & & \\
\hline $\mathrm{Cl}$ & 177 & 6.8 & 1771.2 & & & 0.9636 \\
\hline $\mathrm{H}_{2} \mathrm{O}$ & 3585 & $x_{3} \cdot x$ & 4 & 3630 & ${ }_{2} \mathrm{O}$ & 0.9812 \\
\hline $\mathrm{H}_{2} \mathrm{O}$ & & 8.2 & 4 & 3639 & $\mathrm{I}_{2} \mathrm{O}$ & $0.98 \mathrm{x}$ \\
\hline $\mathrm{H}_{2} \mathrm{O}$ & 89.1 & $5 . x$ & 74.1 & 42.87 & $\mathrm{ICl} .40 \mathrm{OH}_{2} \mathrm{O}$ & 0.95 \\
\hline
\end{tabular}

These values are in remarkably close agreenent with those found from Marignac's ${ }^{1}$ formula for the molectlar heat $\left(K_{M}^{\prime}\right)$ of hydrochloric acid solutions, his calculated values for the 50 , 100 and $200 \mathrm{H}_{2} \mathrm{O}$ solutions being, respectively, 874, I773 and $357^{2}$, whereas the values which we find

"C. Marignac, "Oeuvres Completes," 2, 479, reprinted from Bibl. Univ. Archives, $39,238(1870)$. 
are 873.0, I771.2, and 3571.4 (See Col. 4, Table V). Thomsen's figures are in good agreement for the more concentrated solutions, but his value 3557 for $\mathrm{HCl} .200 \mathrm{H}_{2} \mathrm{O}$ seems to be seriously in error.

An interesting check upon the accuracy of the values $K_{\mathrm{M}}-K_{\mathrm{M}}^{\prime}$ is afforded by the several results for $\mathrm{HCl}$. $100 \mathrm{H}_{2} \mathrm{O}$ and $\mathrm{HCl} .200 \mathrm{H}_{2} \mathrm{O}$ obtained in different ways. For the more concentrated of these 2 solutions 3 values of the specific heat are obtained, $0.9634,0.9633,0.9636$. A direct determination of the specific heat of this same solution gave $0.9634{ }^{2}$ The more dilute solution, namely, $\mathrm{HCl} .200 \mathrm{H}_{2} \mathrm{O}$, gave 0.9812 , whereas a direct determination of this solution gave $0.9814 .^{3}$

This agreement is as satisfactory as could be expected and leads one to infer that the last figure given in the last column of Table $V$ is not likely to be much in error. Taking account of the possible causes of uncertainty, one may guess that the specific heats are probably determined within $0.05 \%$.

Although the specific heats depending upon $K_{\mathrm{M}}-K_{\mathrm{M}}^{\prime}$ derived from $\Delta t_{2}-\Delta t_{1}$ are thus apparently trustworthy within one cal. $/{ }^{\circ} \mathrm{C}$. or thereabouts, the values of the heats of dilution are apparently not so accurate. A comparison of two cases in the last column of Table IV points to a larger error. Subtracting the mean (480) of the fourth and fifth figures in that column from the third figure (108r) we get the value 6or for the heat of dilution of $\mathrm{HCl}$. Io $\mathrm{H}_{2} \mathrm{O}$ to $\mathrm{HCl}: 20 \mathrm{H}_{2} \mathrm{O}$. On the other hand, subtracting the seventh figure (552) in that column from the sixth (I 159 ) we get the value 607 for the same dilution. This is a discrepancy of nearly a per cent. One possible explanation for the consistency of the differential values and the less satisfactory consistency of the single values is to be found in the fact that the experiments with the $\mathrm{roH}_{2} \mathrm{O}$ and $2 \mathrm{OH}_{2} \mathrm{O}$ solutions were done at different times and under somewhat different conditions whereas the $\Delta t_{2}$ and $\Delta t_{1}$ values in any one case were determined immediately after one another in any one instance, and all the conditions were as nearly as possible identical. The chief cause of the large error of the single values is, however, the widely different effect of error in thermometric reading or calibration on the 2 results. An error of $0.001^{\circ}$ in $\Delta t_{1}$ with $\mathrm{HCl} .200 \mathrm{H}_{2} \mathrm{O}$ would cause an error of nearly 4 calories in $U$, whereas it would cause an error of only one cal. $/{ }^{\circ} \mathrm{C}$. in the case of $K_{\mathrm{M}}-K^{\prime}{ }_{\mathrm{M}}$ and but 0.0003 difference in the specific heat of the dilute solution $\mathrm{HCl}$.$200 \mathrm{H}_{2} \mathrm{O}$. Evidently the agreement of the results is, therefore, as good as could be expected.

As regards the relationship of the figures one to another, attention may

'J. Thomsen, "Thermochemische Untersuchungen," I, 39 (1882), reprinted from Aus. Pogg. Ann., 142, 337-379 (1875).

2 Richards and Rowe, Proc. Am. Acad., 49, 173 (19r3).

${ }^{3}$ Loc, cit. 
be called to the fact that in every case the heat of dilution increases with rise of temperature. This signifies that in every case the total heat capacity of the reacting substances decreases during the act of dilution, a fact which was pointed out by Thomsen ${ }^{1}$ and Marignac ${ }^{2}$ long ago, but is worthy of reiteration. Modern theory, of course, refers this decrease of heat capacity to increase of ionization. The phenomenon is exactly opposite to that which occurs during neutralization, when the total sum of the heat capacities of acid and alkali (each containing roo $\mathrm{H}_{2} \mathrm{O}$ per mol) increases by about 49 cal./th. when the 2 ions $\mathrm{H}^{\prime}$ and $\mathrm{OH}^{\prime}$ disappear. The actual loss of heat capacity when $\mathrm{HCl}$. $10 \mathrm{H}_{2} \mathrm{O}$ (perhaps $40 \%$ ionized) is diluted to $\mathrm{HCl} .100 \mathrm{H}_{2} \mathrm{O}$ (perhaps $77 \%$ ionized) is of the same order as would be predicted from the gain of heat capacity on neutralization, although not exactly concordant.

Another interesting circumstance is the fact that the change of heat capacity on dilution of such a case as $\mathrm{HCl}$. $\mathrm{IO}_{2} \mathrm{O}$ bears an almost linear relation to the mol-fraction of hydrochloric acid in the diluted solution, when the solution is dilute. The most convenient means of exhibiting this relationship is to plot $K_{M}-K_{M}^{\prime}$ (taken from Table V) in relation

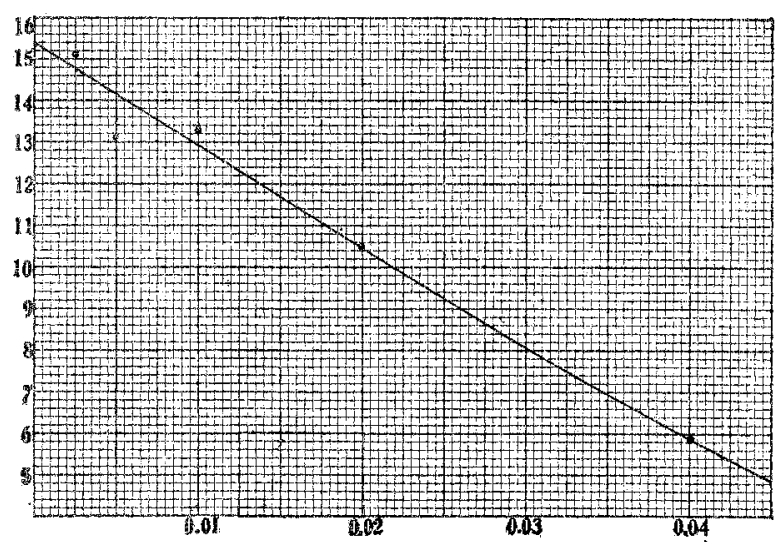
to the fraction of a mol. of hydrochloric acid corresponding to a mol. of water. This is shown in the accompanying diagram, Fig. 2. With more concentrated solutions the relation is by no means linear, because of decreasing dissociation; ${ }^{3}$ but the relation indicated by

Fig. 2.-Change of heat capacity on dilution of $\mathrm{HCl}$. the almost straight $\mathrm{xoH}_{2} \mathrm{O}$. Fractions of mol HCl per $\mathrm{x} \mathrm{mol} \mathrm{H} \mathrm{H}_{2} \mathrm{O}$ plotted as line for concentrations abscissas (the amount of water being that in the final dilute between $\mathrm{HCl} .25 \mathrm{H}_{2} \mathrm{O}$
solution). $K_{\mathrm{M}}-K^{\prime} \mathrm{M}$ plotted as ordinates.

and very dilute solutions falls within the limit of experimental error of every one of the values for $K_{M}-K_{M}^{\prime}$. This diagram has the further convenience of making possible the computation of the specific heats of any solution of hydrochloric

'J. Thomsen, "Thernochemische Untersuchungen," I, 39 (1882); reprinted from A us. Pogg. Ann., 142, 337-379 (1871).

"C. Mariguac, "Oetvres Completes," 2, p. 479, reprinted from Bibl. Uniw. Archives, $39,238(1870)$.

\& Tucker (loc. cil.) has found a simple expression for calculating the specific heats of solutions more concentrated than $\mathrm{HCl} .{ }_{5} \mathrm{H}_{8} \mathrm{O}$. 
acid between $\mathrm{HCl} .25 \mathrm{H}_{2} \mathrm{O}$ and infinite dilution. All that one has to do is to read off on the curve the value of $K^{\prime}-K$, which corresponds to the particular solution. This value is subtracted from the heat capacity 162.9 (the heat capacity of $\mathrm{HCl}$. $\mathrm{H}_{2} \mathrm{O}$ ) and the result added to that of the additional water. The result is then the heat capacity of the dilute solution, and when divided by the total molal weight of this solution gives its specific heat. For example, required the specific heat of the solution $\mathrm{HCl}_{4} \mathrm{O} \mathrm{H}_{2} \mathrm{O} . \quad K_{\mathrm{M}}-K^{\prime}{ }_{\mathrm{M}}$ is found from the curve to be 9.2. Hence, $(162.9+540.0-9.2) / 757.0=0.9164=$ the calculated specific heat of $\mathrm{HCl}_{4} \mathrm{O}_{2} \mathrm{O}$.

Further theoretical considerations bearing upon these figures will be reserved for a later communication.

Many other similar dilution experiments have been carried out by this method upon the following substances: nitric acid, lithium, sodium and potassium hydroxides; lithium, sodium, potassium and cesium chlorides; lithium, sodium, potassium and cesium nitrates.

These results enable one to calculate the specific heats of a great variety of solutions as well as to calculate the change of the heat of neutralization with the change of temperature. Heats of neutralization themselves have likewise been determined in an extended investigation, using the calorimeter combination $A$ a described above, which proved itself especially suitable for this work. These results will be collated and published as soon as time can be found for the considerable task.

We take pleasure in acknowledging our indebtedness to the Carnegie Institution of Washington for important financial assistance in this extended and expensive investigation.

\section{Summary.}

In this paper the indirect method of determining specific heats of dilute solutions by measuring their heat of dilution at 2 different temperatures has been carried into effect. By its means the specific heats of a great number of acids, alkalies and salts have been determined with a degree of accuracy as regards the more dilute solutions of perhaps $0.05 \%$. The results for hydrochloric acid, which alone are given in this preliminary paper, are as follows: $\mathrm{HCl} . \mathrm{IOH}_{2} \mathrm{O}, 0.752 ; \mathrm{HCl} .2 \mathrm{OH}_{2} \mathrm{O}, 0.849$ (these two the basis of computation); $\mathrm{HCl}_{2}{ }_{5} \mathrm{H}_{2} \mathrm{O}, 0.8776 ; \mathrm{HCl}_{5} \mathrm{OH}_{2} \mathrm{O}, 0.9320$; $\mathrm{HCl} .100 \mathrm{H}_{2} \mathrm{O}, 0.9634 ; \mathrm{HCl} .200 \mathrm{H}_{2} \mathrm{O}$, $0.9812 ; \mathrm{HCl} .400 \mathrm{H}_{2} \mathrm{O}, 0.9905$. The paper is nevertheless rather an indication of an advantageous method than a final contribution. With the experience gained, yet more accurate results may be obtained in the future. 